\title{
Experimental Investigation on Fuel Coolant Interaction Using Simulant Ceramic Melts in Water: Insights and Conclusions
}

\author{
Nitendra Singh ${ }^{1,2 *}$, Arun K. Nayak ${ }^{1,2}$, Parimal P. Kulkarni' \\ ${ }^{1}$ Homi Bhabha National Institute, Mumbai, India \\ ${ }^{2}$ Bhabha Atomic Research Centre, Reactor Engineering Division, Mumbai, India \\ Email: *nitendrasingh1988@gmail.com
}

How to cite this paper: Singh, N., Nayak, A.K. and Kulkarni, P.P. (2020) Experimental Investigation on Fuel Coolant Interaction Using Simulant Ceramic Melts in Water: Insights and Conclusions. World Journal of Nuclear Science and Technology, 10, 139-157.

https://doi.org/10.4236/wjnst.2020.104013

Received: March 5, 2020

Accepted: September 7, 2020

Published: September 10, 2020

Copyright $\odot 2020$ by author(s) and Scientific Research Publishing Inc. This work is licensed under the Creative Commons Attribution International License (CC BY 4.0).

http://creativecommons.org/licenses/by/4.0/ (c) (i) Open Access

\begin{abstract}
Steam explosion is one of the crucial and poorly understood phenomena which may occur during severe accident scenario and may lead to containment failure. In spite of several experimental and analytical studies, the root cause of steam explosion has not been understood. Recent claims in the literature suggest that the presence of fine fragmentation during steam explosion causes its occurrence. In order to investigate this and understand the root cause of steam explosion, series of experiments were performed with $50 \mathrm{~g}$ to $2500 \mathrm{~g}$ of $\mathrm{CaO}-\mathrm{B}_{2} \mathrm{O}_{3}$, a corium simulant in 4.5 litre of water. It was observed that steam explosion may occur even in the absence of fine fragments, which is contrary to the claims in the literature. To investigate further, conversion efficiency analysis was performed. This suggested that the amount of thermal energy converted to mechanical energy is more important deciding factor in explaining the occurrence of steam explosion. The present study discusses the importance of conversion efficiency in deciding steam explosion and also gives a new perspective to look at steam explosion phenomenology.
\end{abstract}

\section{Keywords}

Severe Accident, Core Catcher, Steam Explosion, Fuel Coolant Interaction, Fragmentation

\section{Introduction}

Nuclear industry always strives for safety of power plants during normal operation as well during accidental scenarios. Prior understanding of phenomena involved during accidents helps designers to take necessary preventive counter measure. One such phenomenon needing deep understanding is fuel-coolant 
interaction (FCI). During a severe accident, large amounts of corium consisting of molten nuclear fuel and structural material may come in contact with subcooled water leading to fuel-coolant interaction. In spite of many years of earnest efforts to prevent a core-melt accident, after Fukushima Daiichi accident, it seems realistic that such an accident could occur. It is clear that the structural integrity of containment during such accidents has to be maintained [1]. There is a concern that due to FCI, steam explosions may occur, which may threat the integrity of containment due to dynamic pressure loads. Thus, steam explosion should be understood and should be avoided to occur so as to minimize its consequences.

Steam explosion occurs when rapid heat transfer between the melt and coolant occurs. It progresses in four distinct phases as described by [1] [2] [3] [4] as follows:

1) Premixing phase

In this phase, the melt and coolant interact and undergo fragmentation owing to the hydrodynamic forces which result from Rayleigh-Taylor and KelvinHelmholtz instabilities of the system. Due to high melt temperature, a vapour blanket insulates the melt from water and hinders subsequent heat transfer. This meta-stable state is usually referred as the premixing phase (Figure 1(a)).

2) Triggering phase

The event which destabilizes the vapour blanket such that the melt and coolant comes in contact is called as trigger. Due to this vapour film collapse, there is a rapid heat transfer and rapid rise in pressure in some local small region. Film destabilization may occur due to external pressure pulse resulting from impact of melt on bottom of the tank or vessel, thermal film destabilization, and coolant entrapment within the melt. This stage is called as the triggering phase (Figure $1(b))$.

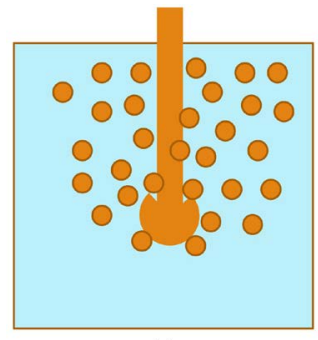

(a)

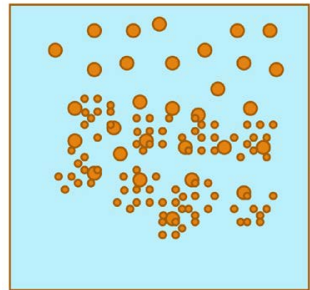

(c)

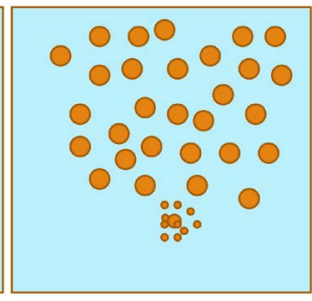

(b)

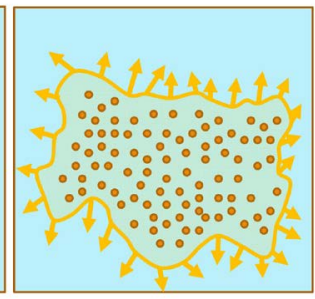

(d)

Figure 1. Steam explosion and its phases of occurrence. (a) Premixing phase; (b) Triggering phase; (c) Propagation phase; (d) Expansion phase. 


\section{3) Propagation phase}

In favourable circumstances, the pressure pulse from previous phase can escalate further vapour film collapse leading to further heat transfer and rapid pressure rise. This propagating pressure pulse collapses the vapour blankets around the melt fragments present in the premixture, causing coherent energy release and further fragmentation of melt. This results in intense heat transfer from the melt to coolant. This process is known as the propagation phase (Figure $1(\mathrm{c})$ ).

4) Expansion phase

Further swelling of high pressure mixture behind the propagation front against the inertial constraints imposed by the surroundings leads to the potential to cause damage to any surrounding structures. This phase is generally called as the expansion phase (Figure 1(d)).

Steam explosion has been studied intensively for a few decades mainly with a focus as the premixing phase of energetic steam explosions [5]-[10]. They suggest that the melt will undergo coarse and fine fragmentation during the interaction of melt with water. They observed steam explosions with alumina but not with corium due to difference in fragmentation behaviour. Those works provided a comprehensive database for the debris formation and its size distribution. A series of experiments were carried out at various laboratories across the globe as reviewed by [4] [11] [12]. [13] studied the effect of metallic melt on steam explosion behaviour. Similar program called MISTEE (Micro-Interactions in Steam Explosion Experiments) was carried out at KTH, Stockholm [1]. The objective of the steam explosion study at KTH was to develop a basic understanding of micro-interactions in steam explosion, with a hope to identify mechanisms which may limit the explosivity of molten corium in a prototypic severe accident scenario with FCI. Experiments in FARO, KROTOS and TROI suggested that physical properties of corium $\left(\mathrm{UO}_{2}-\mathrm{ZrO}_{2}\right.$ as a binary oxidic material) may have been responsible for its low explosivity. The evidence is however far from being conclusive, so that extrapolation of the observed behaviour to reactor scenarios is not possible without an in-depth understanding. In the ALPHA program ([14] [15]) initiated at JAERI (Japan Atomic Energy Research Institute) in Japan, they focussed their study to investigate better strategy for safe corium cooling. The ALPHA program suggested that void fraction during premixing plays an important role in deciding the occurrence of steam explosion. They also observed that steam explosion was not observed with saturated water. Their conclusive remark was that the explosive interaction in stratified configuration was less energetic compared to that in melt drop configuration. The PREMIX (FZK, Germany) experiments have been performed to study the premixing of sizable amounts of very hot oxidic melts with water when being released as a jet in a reasonably characterized way and with full optical access. PREMIX involves the full physics of the mixing process including jet break-up and melt drop fragmentation using Alumina melt. KROTOS tests [16] were carried out on molten alumina and prototypic melts. These tests brought out that, no spontaneous ex- 
plosion is possible in case of corium and a trigger was needed. Also, the effect of coolant temperature was highlighted. The recent study by [17] [18] [19] [20] provided additional information. They performed a series of experiments with a focus on the fractions of particulate debris and the agglomerate on the pool bottom as well as the debris size distribution during FCI.

However, all these studies are unable to explain the conditions for steam explosion. Moriyama [21] suggested that steam explosion occurs when the fine fragments i.e. the particles of the order of $0.1 \mathrm{~mm}$ in size or below formed during fragmentation and constitute about $10 \%-50 \%$ on debris mass, considering the history of melt fragmentation in the prior experiments, as shown in Figure 2.

This raises a question, is the fine fragmentation a root cause of steam explosion?

To investigate this, a series of experiments were performed by us to study the fragmentation behaviour of ceramic oxides in water and the effects of melt-to-water ratio on it. Several experiments were performed while varying the melt masses from $50 \mathrm{~g}$ to $2500 \mathrm{~g}$ and keeping the constant water volume of 4.5 litres. All these experiments were performed in two different facilities having two different test set-ups for smaller and higher melt masses.

\section{Simulant Materials}

Considering the difficulty associated with prototypic melts to perform experiments due to unavailability of prototypic materials, radioactivity issues and of course the cost involved in melting, simulant oxides (corium simulants) were used by many researchers in the past. They have been considered for the present experiments. CaO- $\mathrm{B}_{2} \mathrm{O}_{3}$ is a non-eutectic mixture (in ratio of 30:70 respectively by weight) and a corium simulant formed and tested at KTH, Sweden [22]. The transient heat transfer behaviour from the melt to coolant depends strongly on the thermal diffusivity of the material, and $\mathrm{CaO}-\mathrm{B}_{2} \mathrm{O}_{3}$ has the thermal diffusivity comparable to corium Table 1 [22].

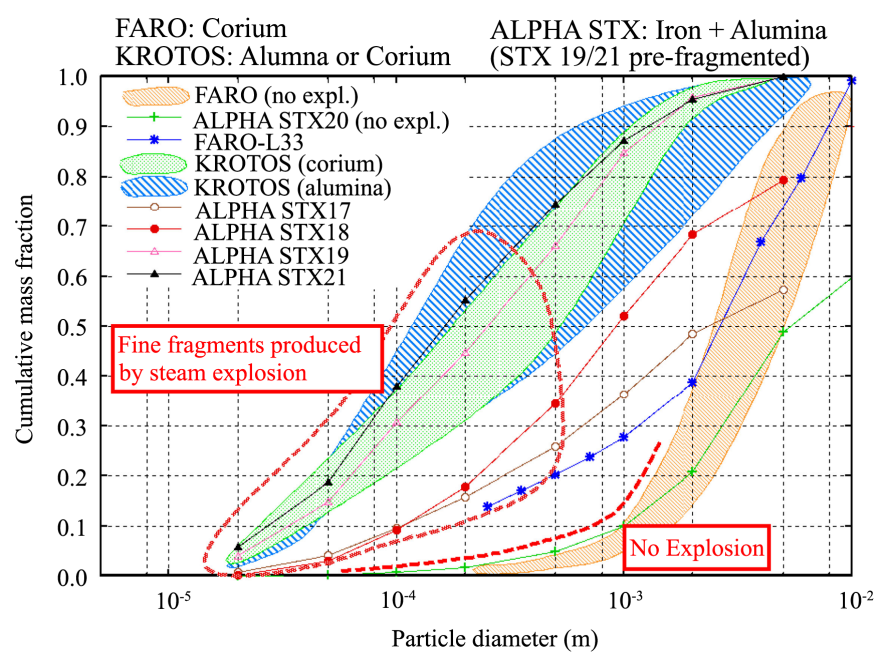

Figure 2. Moriyama's map for steam explosion condition. 
Table 1. Properties of simulant material.

\begin{tabular}{cccc}
\hline Property & Units & $\mathrm{CaO}-\mathrm{B}_{2} \mathrm{O}_{3}$ & Corium \\
\hline Density & $\mathrm{kg} \cdot \mathrm{m}^{-1}$ & 2500 & 8800 \\
Liquidus Temperature & $\mathrm{K}$ & 1300 & 2850 \\
Specific Heat & $\mathrm{J} \cdot \mathrm{kg}^{-1} \cdot \mathrm{K}^{-1}$ & 1530 & 565 \\
Fusion Heat & $\mathrm{kJ} \cdot \mathrm{kg}^{-1}$ & 460 & 362 \\
Thermal Conductivity & $\mathrm{W} \cdot \mathrm{m}^{-1} \cdot \mathrm{K}^{-1}$ & 2 & 2.88 \\
Thermal Diffusivity & $\mathrm{m}^{2} \cdot \mathrm{s}^{-1}$ & $5.229 \mathrm{E}-07$ & $5.792 \mathrm{E}-07$ \\
\hline
\end{tabular}

\section{Experimental Set-Ups}

Experiments were performed in two different set-ups for the small and large amount of the melt volumes.

The first set-up consisted of a small induction melt generator attached to the test section. $\mathrm{CaO}-\mathrm{B}_{2} \mathrm{O}_{3}$ mixture was melted in the induction furnace and was poured into the test section using specially designed fast acting valve arrangements. The test section was a steel vessel with transparent observation window. The test section was of 6 litres water capacity $(150 \mathrm{~mm} \times 150 \mathrm{~mm} \times 300 \mathrm{~mm})$ as shown in Figure 3. It was instrumented with a piezoelectric dynamic pressure transducer (Make: PCB, model-101A05, S/N 6449) to record the dynamic pressure within the water pool.

The second set-up for large melt volumes consisted of the furnace and the test section of 12 litres water capacity. The melt was generated in the furnace and poured into the test section. The test section was a steel vessel of $130 \mathrm{~mm}$ diameter and $500 \mathrm{~mm}$ height as shown in Figure 4. It was instrumented with a piezoelectric pressure transducer to record the dynamic pressure within the water pool.

\section{Results}

Results of the experiments conducted are presented here. These results are bulleted on the basis of melt-to-water ratio in each experiment. About $50 \mathrm{~g}$ to 2500 $\mathrm{g}$ of melt was poured into 4.5 litres of water pool to understand the influence of melt-to-water ratio on FCI. The water pool temperature was also maintained at about $300 \mathrm{~K}$ in all the experiments.

\subsection{Melt-to-Water Ratio of 0.011 (Melt Mass $=50 \mathrm{~g}$; Water Mass = $4500 \mathrm{~g}$ )}

About $50 \mathrm{~g}$ of $\mathrm{CaO}-\mathrm{B}_{2} \mathrm{O}_{3}$ was melted and heated up to $1500^{\circ} \mathrm{C}$ so as to ensure that the mixture is completely melted and having sufficient super-heat before pouring. The molten simulant was then poured into the test section having the water pool as shown in Figure 5. No dynamic pressure peak was observed in this case. 


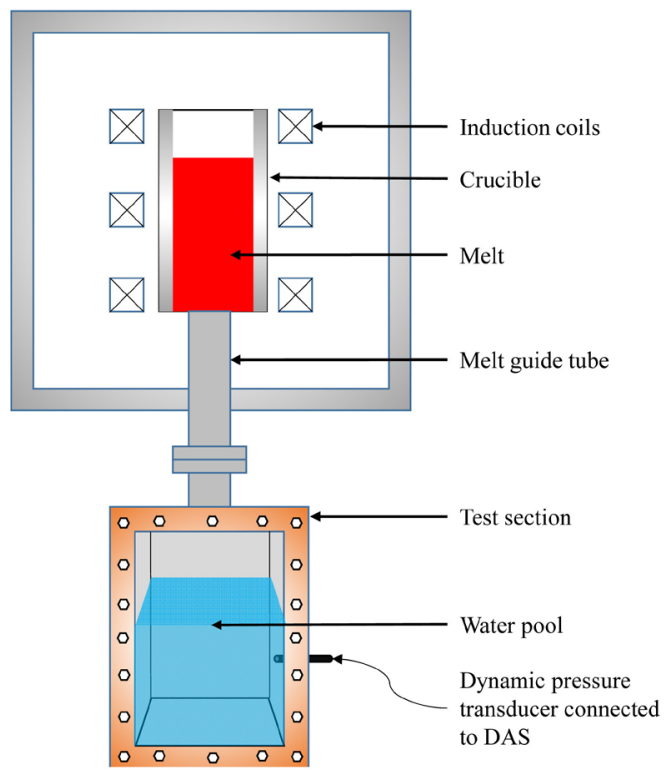

Figure 3. Test section for conducting small melt volume experiments (schematic).

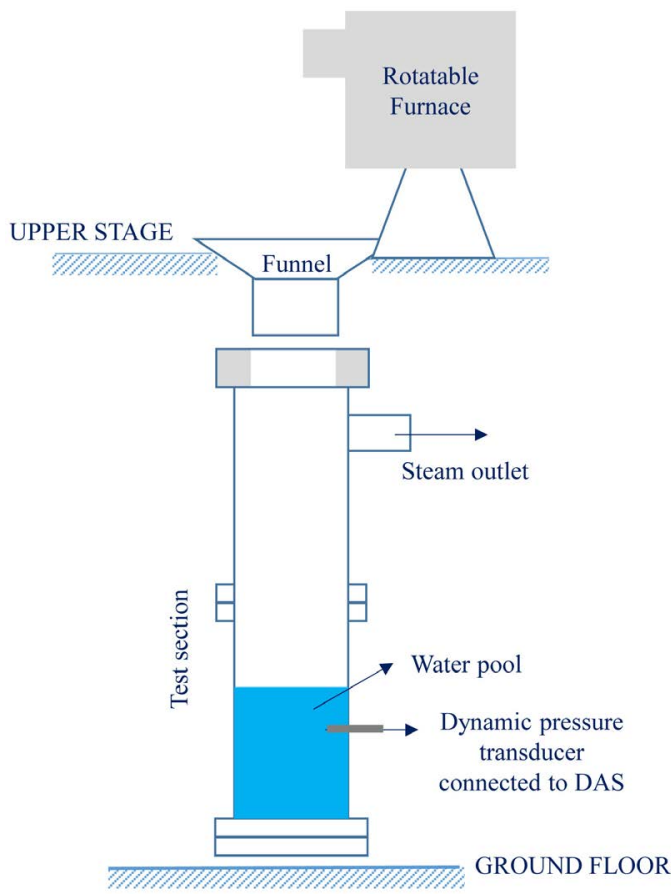

Figure 4. Test section for large melt volume FCI experiments (shematic).

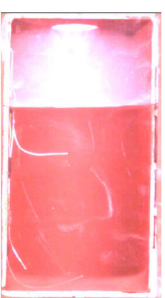

$0.84 \mathrm{~s}$

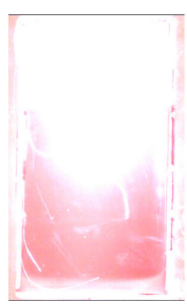

$0.88 \mathrm{~s}$

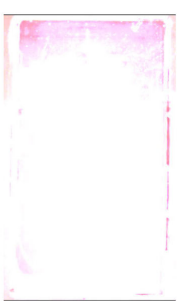

$1.55 \mathrm{~s}$

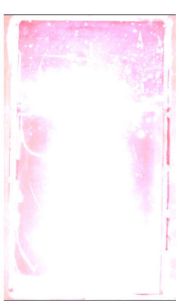

$1.70 \mathrm{~s}$

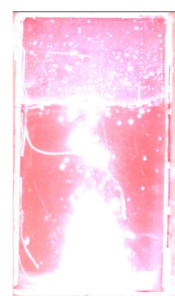

$2.00 \mathrm{~s}$

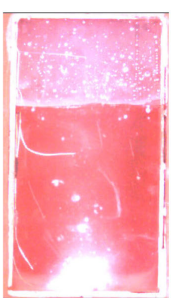

$2.56 \mathrm{~s}$

Figure 5. Visuals from high speed shooting of FCI. 
After opening the test section, fine particulate and porous globular debris were obtained as shown in Figure 6. The debris mainly constituted large porous globular structure and some fine crystals (formed mainly because of crushing of surfaces of larger debris). Such globular debris may have formed due to ballooning effect caused by the generated steam while interacting with molten material. This also led to the formation of porosity within these debris. Due to this ballooning effect, there is an increase in area of melt-water contact from both sides (inside and outside walls of globular debris), and hence rapid heat transfer from melt to the water. The debris were so fragile that most of them were breaking even while handled softly, and contributed to fine particulate.

To further analyze the debris, microscopic analysis was performed as shown in Figure 7, which shows the morphology and particulate diameters. It is clearly visible that along with the porous and globular debris, some fine solid round particles were also present. However, the diameter of these solid round particles were close to $0.5-1 \mathrm{~mm}$. Figure 8 presents the enlarged images of fine particulates which also includes strands known as Pele's hair, observed during the experiment. The presence of Pele's hairs suggests high shear between the melt and steam formed during the interaction. The size distribution of the globules is shown in Figure 9. It was observed that porous globule sizes ranging from 1.5 $\mathrm{mm}$ diameter to $23 \mathrm{~mm}$ diameter were observed, most of them lie in between 2 $\mathrm{mm}$ to $9 \mathrm{~mm}$ diameter.
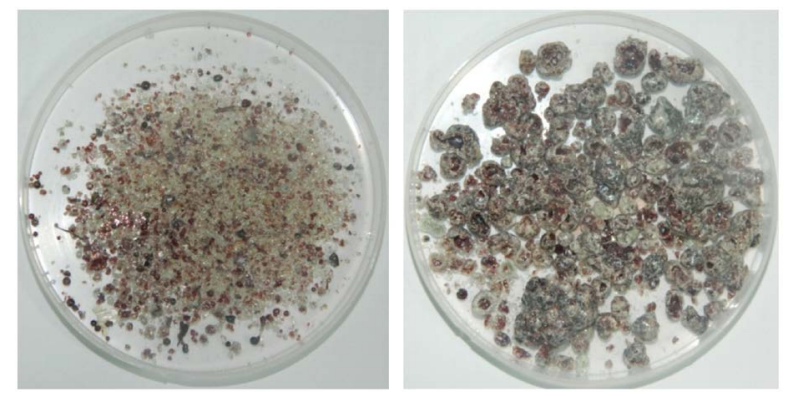

Figure 6. Fine particulate and porous globular debris of small volume experiment (Scale: $1 \mathrm{~cm}$ of image $=2 \mathrm{~cm}$ of actual size).

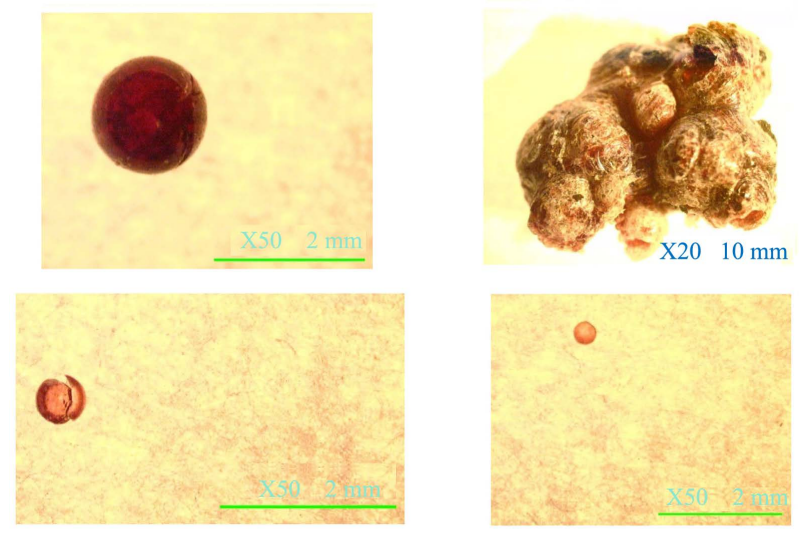

Figure 7. Microscopic analysis of debris from small melt volume experiment. 


\subsection{Melt-to-Water Ratio of 0.11 (Melt Mass $=\mathbf{5 1 5} \mathrm{g}$; Water Mass $=$ $4500 \mathrm{~g}$ )}

In this case, about $515 \mathrm{~g}$ of $\mathrm{CaO}-\mathrm{B}_{2} \mathrm{O}_{3}$ was melted and heated nearly up to $1200^{\circ} \mathrm{C}$ and was poured into 4.5 litres of water pool. No dynamic pressure peak was observed in this case, shown in Figure 10.

The debris obtained after opening the test section were analysed. Porous globular debris of sizes ranging from a few $\mathrm{mm}$ to $25 \mathrm{~mm}$ were obtained; along with long thread like structures formed due to shear between melt and steam known as Pele's hair were obtained (Figure 11). Most prominent range of particles was observed between 5 to $15 \mathrm{~mm}$ as shown in Figure 12 .

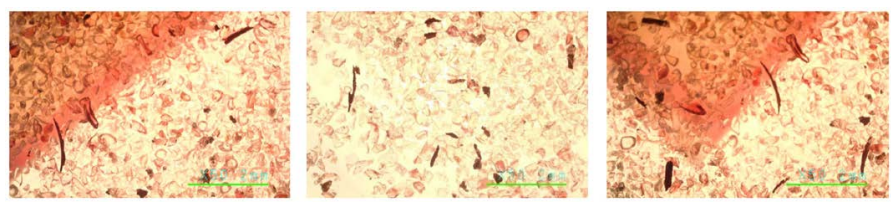

Figure 8. Microscopic analysis of fine particulate of small melt volume experiment.

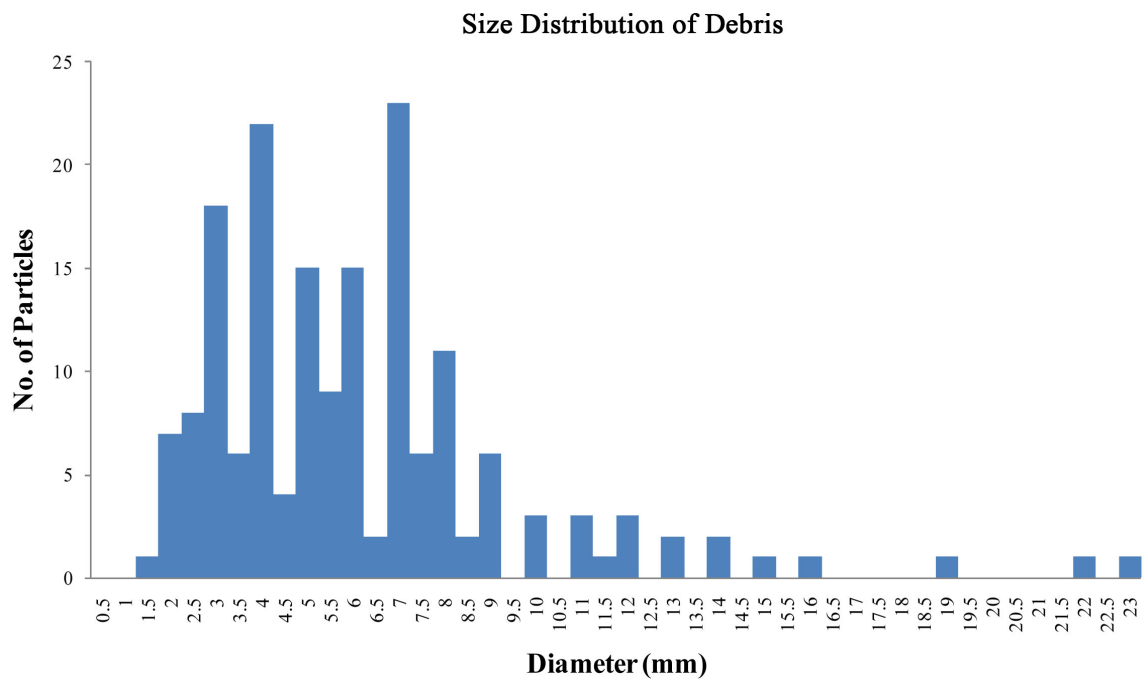

Figure 9. Debris particle size distribution of small melt volume experiment.

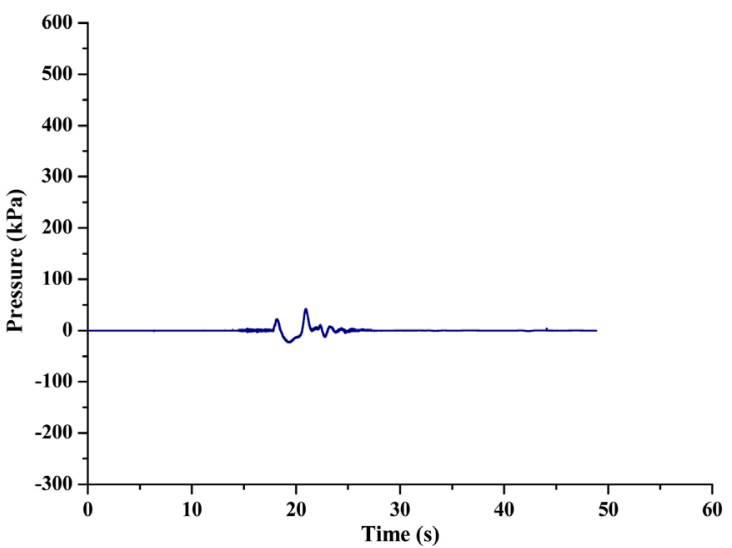

Figure 10. Dynamic pressure peak versus time curve for $\mathrm{M} / \mathrm{W}$ ratio $=0.11$. 


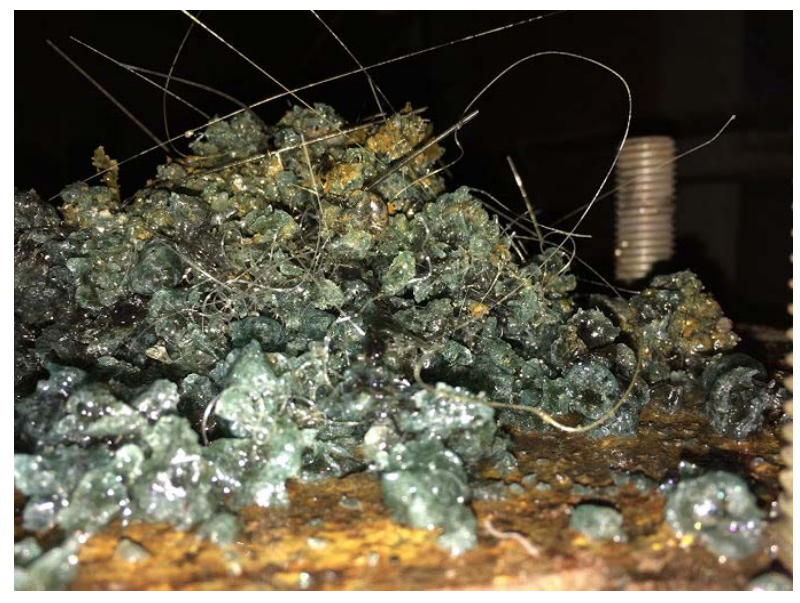

Figure 11. Debris obtained from experiment with $\mathrm{M} / \mathrm{W}=0.11$.

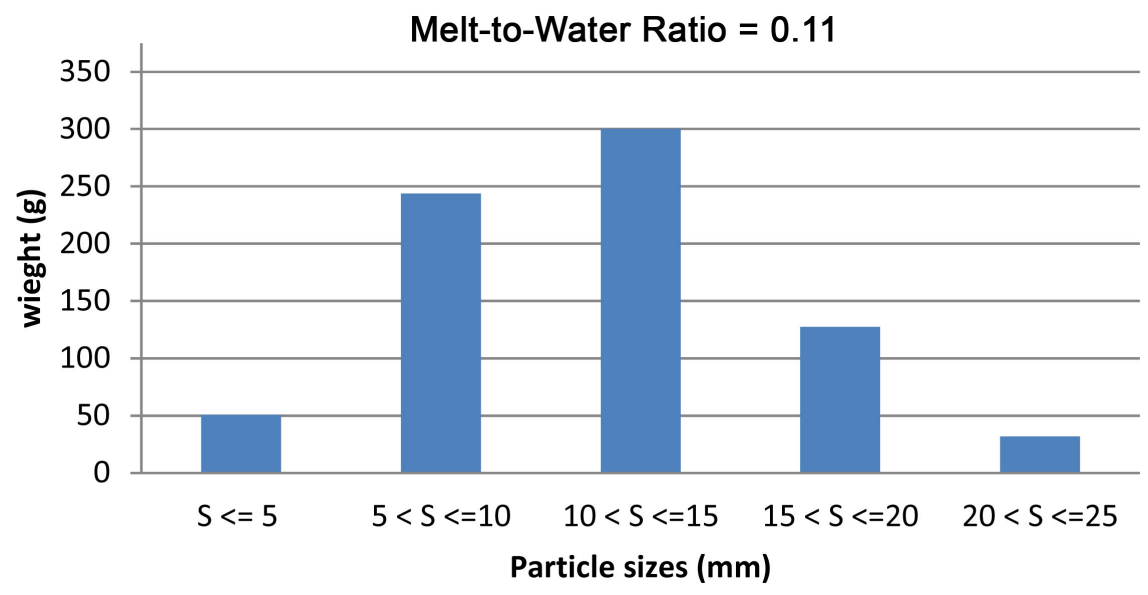

Figure 12. Debris particle size distribution of experiment with $\mathrm{M} / \mathrm{W}=0.11$.

\subsection{Melt-to-Water Ratio of 0.16 (Melt Mass $=710 \mathrm{~g}$; Water Mass = $4500 \mathrm{~g}$ )}

About $710 \mathrm{~g}$ of $\mathrm{CaO}-\mathrm{B}_{2} \mathrm{O}_{3}$ was melted and heated nearly up to $1200^{\circ} \mathrm{C}$ and was poured into similar 4.5 litres of water pool. No dynamic pressure peak was observed in this case, shown in Figure 13.

The debris obtained in this case were porous globular of sizes ranging from a few $\mathrm{mm}$ to $38 \mathrm{~mm}$; along with long thread like structures formed due to high shear between melt and steam known as Pele's hair (Figure 14). Most prominent range of particles was observed between 5 to $20 \mathrm{~mm}$, as shown in Figure 15.

\subsection{Melt-to-Water Ratio of 0.21 (Melt Mass $=925$ g; Water Mass = $4500 \mathrm{~g}$ )}

About $925 \mathrm{~g}$ of $\mathrm{CaO}-\mathrm{B}_{2} \mathrm{O}_{3}$ was melted and heated nearly up to $1200^{\circ} \mathrm{C}$ and was poured into similar 4.5 litres of water pool. Dynamic pressure peak of $506 \mathrm{kPa}$ was observed in this case, shown in Figure 16. This peak has two parts, positive and negative, which aroused mainly due to compression and rarefaction of the pressure wave. This is discussed in detail in the last section of this article. 


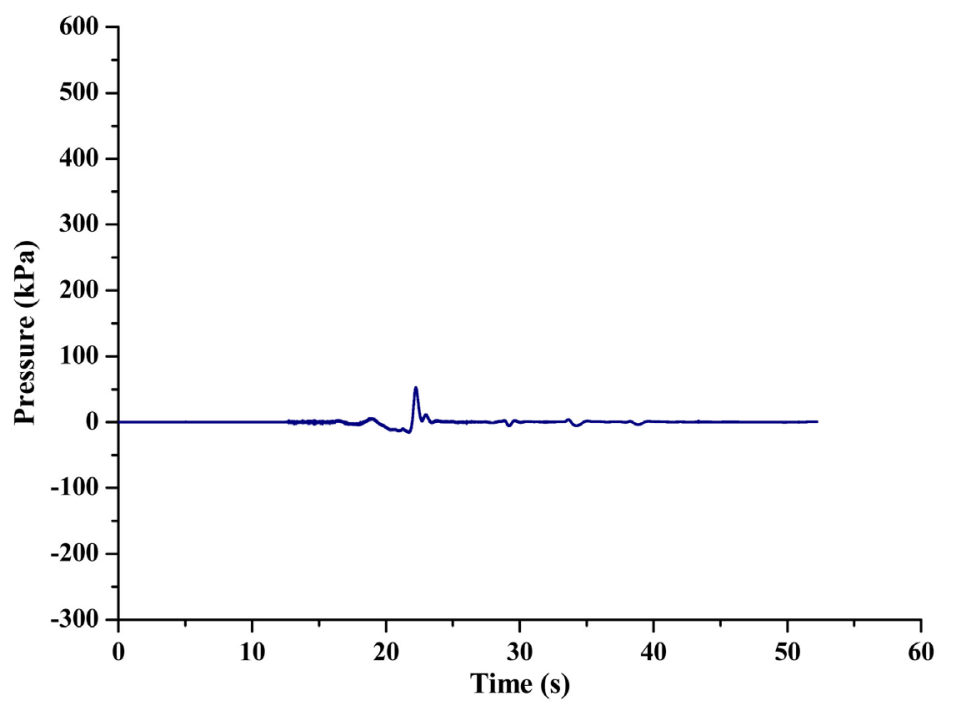

Figure 13. Dynamic pressure peak versus time curve for $\mathrm{M} / \mathrm{W}$ ratio $=0.16$.

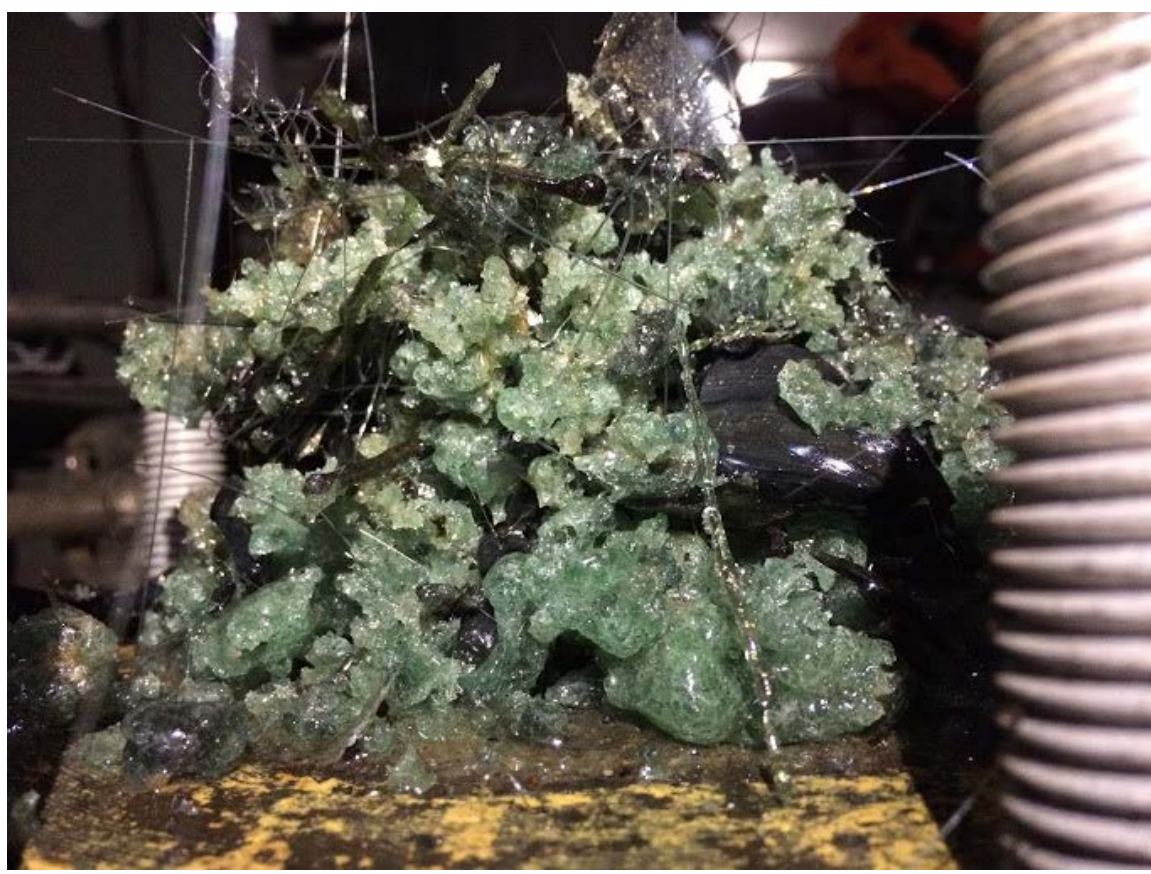

Figure 14. Debris obtained from experiment with $\mathrm{M} / \mathrm{W}=0.16$.

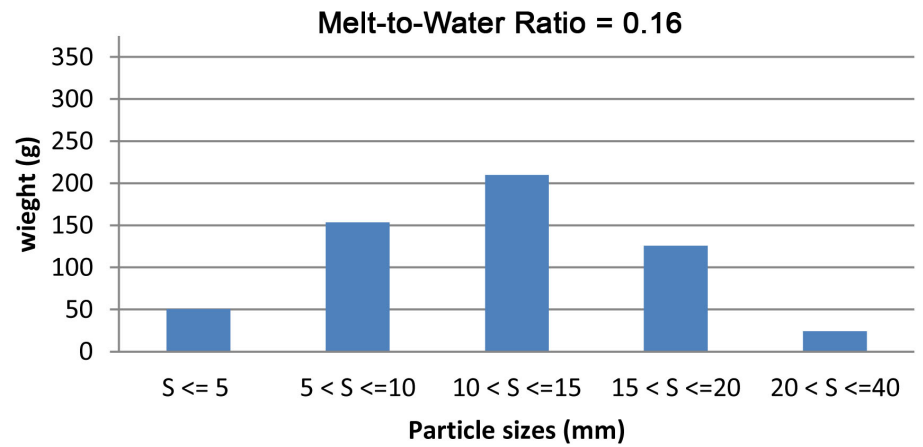

Figure 15. Debris particle size distribution of experiment with $\mathrm{M} / \mathrm{W}=0.16$. 


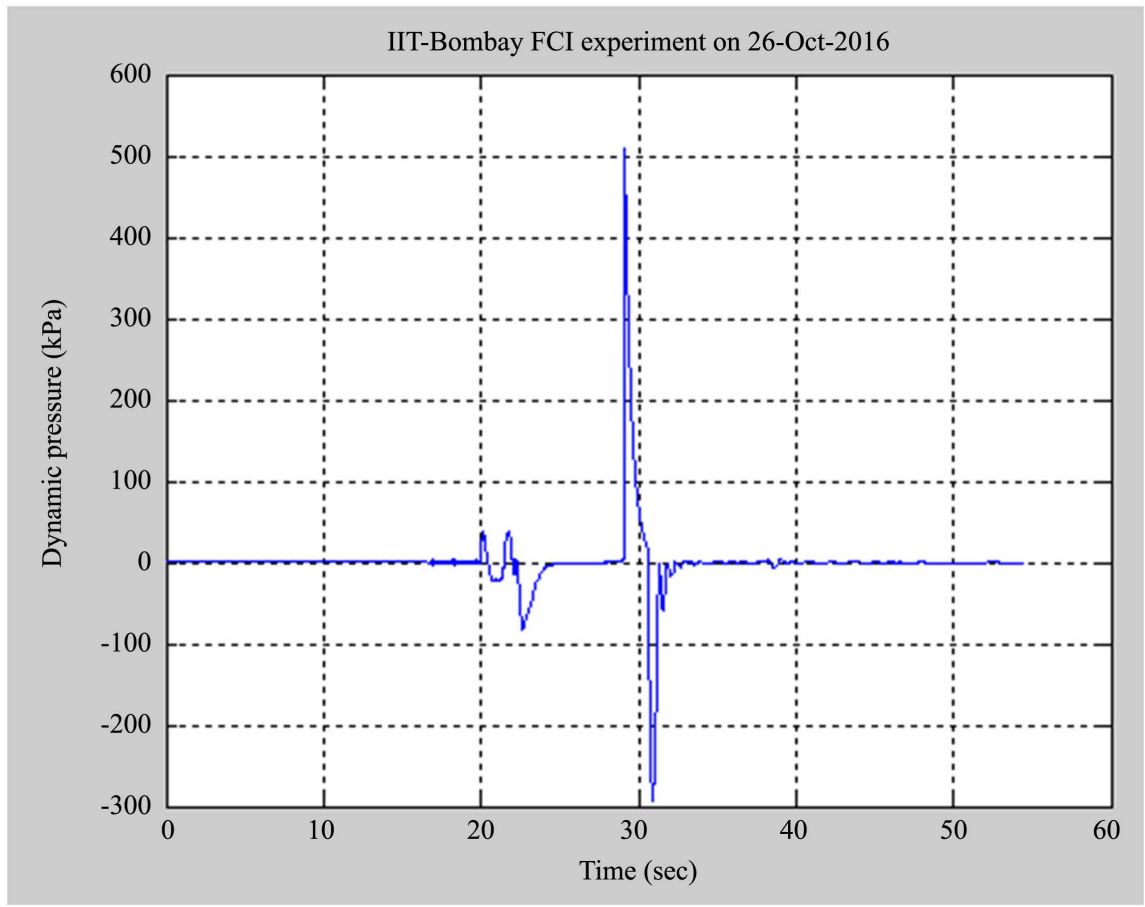

Figure 16. Dynamic pressure peak versus time curve for $\mathrm{M} / \mathrm{W}$ ratio $=0.21$.

The debris obtained in this case were porous globular debris of sizes ranging from a few mm to $42 \mathrm{~mm}$; along with Pele's hair as shown in Figure 17. Number of agglomerated debris was more in this case. Most prominent range of particles was observed between 5 to $20 \mathrm{~mm}$.

\subsection{Melt-to-Water Ratio of 0.41 (Melt Mass = 1846 g; Water Mass $=4500 \mathrm{~g}$ )}

About $1846 \mathrm{~g}$ of $\mathrm{CaO}-\mathrm{B}_{2} \mathrm{O}_{3}$ was melted and heated nearly up to $1200^{\circ} \mathrm{C}$ and was poured into similar 4.5 litres of water pool. Dynamic pressure peak of $467 \mathrm{kPa}$ was observed in this case, shown in Figure 18. Behaviour of the peak was similar to the previous case.

Mostly porous globular debris of sizes ranging from a few $\mathrm{mm}$ to $42 \mathrm{~mm}$ were obtained as shown in Figure 19. Most prominent range of particles was observed between 5 to $30 \mathrm{~mm}$.

\subsection{Melt-to-Water Ratio of 0.51 (Melt Mass $=2285 \mathrm{~g}$; Water Mass $=4500 \mathrm{~g}$ )}

About $2285 \mathrm{~g}$ of $\mathrm{CaO}-\mathrm{B}_{2} \mathrm{O}_{3}$ was melted and heated nearly up to $1200^{\circ} \mathrm{C}$ and was poured into similar 4.5 litres of water pool. Dynamic pressure peak of $510 \mathrm{kPa}$ was observed in this case, shown in Figure 20; with the similar behaviour as it was in previous case.

Porous globular debris of sizes ranging from a few $\mathrm{mm}$ to $42 \mathrm{~mm}$ were obtained as shown in Figure 21. Most prominent range of particles was observed between 5 to $20 \mathrm{~mm}$. 


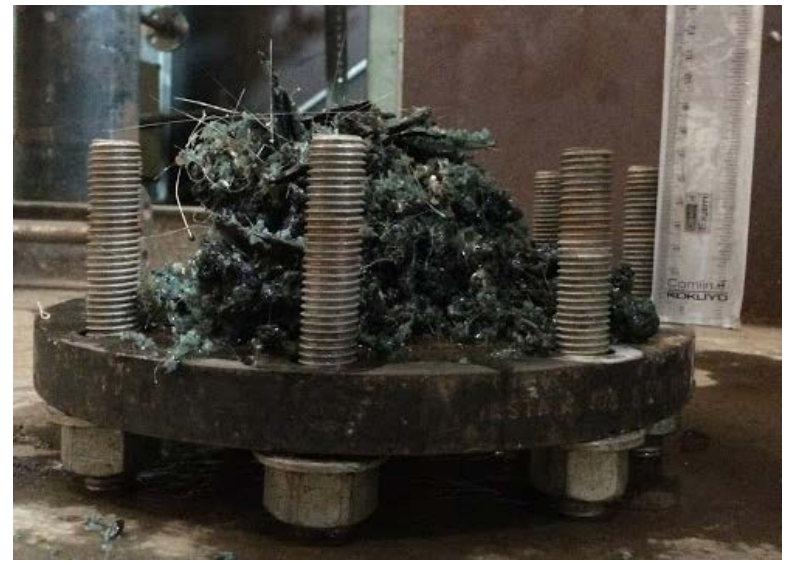

Figure 17. Debris obtained from experiment with $\mathrm{M} / \mathrm{W}=0.21$.

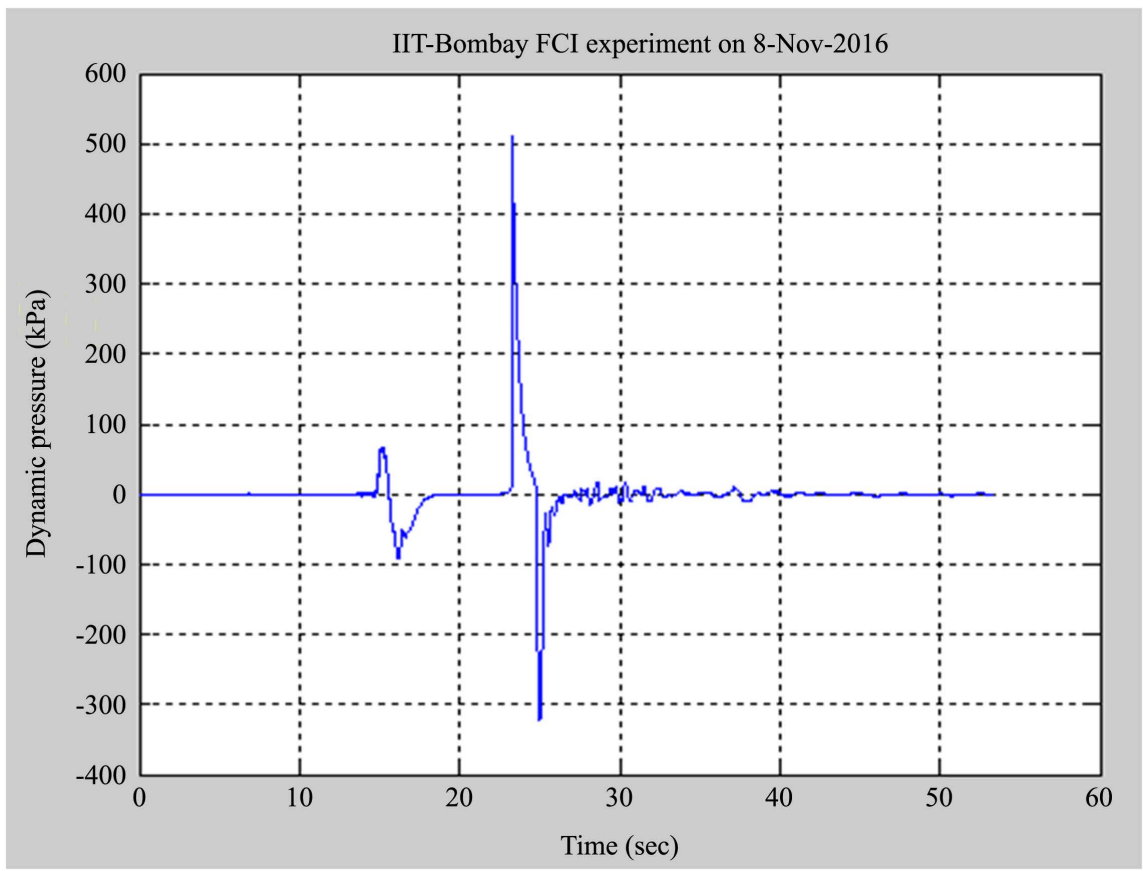

Figure 18. Dynamic pressure peak versus time curve for $\mathrm{M} / \mathrm{W}$ ratio $=0.41$.

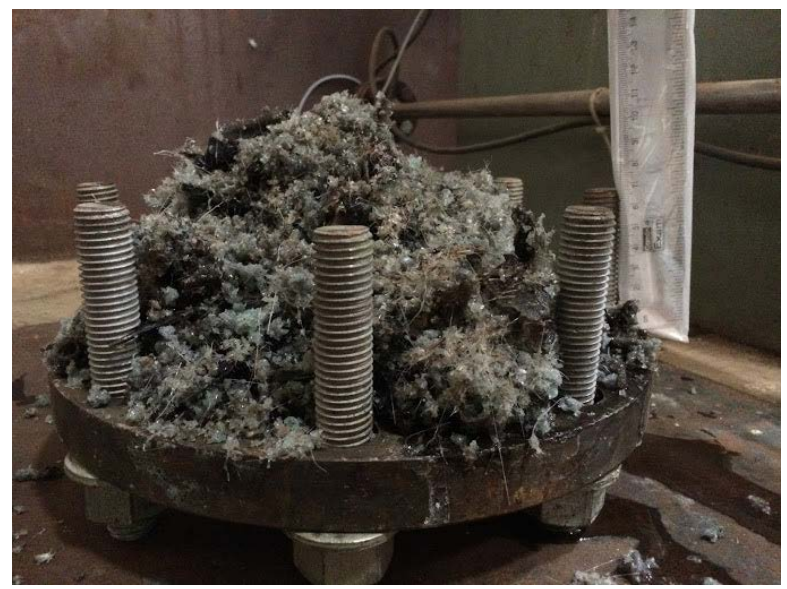

Figure 19. Debris obtained from experiment with $\mathrm{M} / \mathrm{W}=0.41$. 


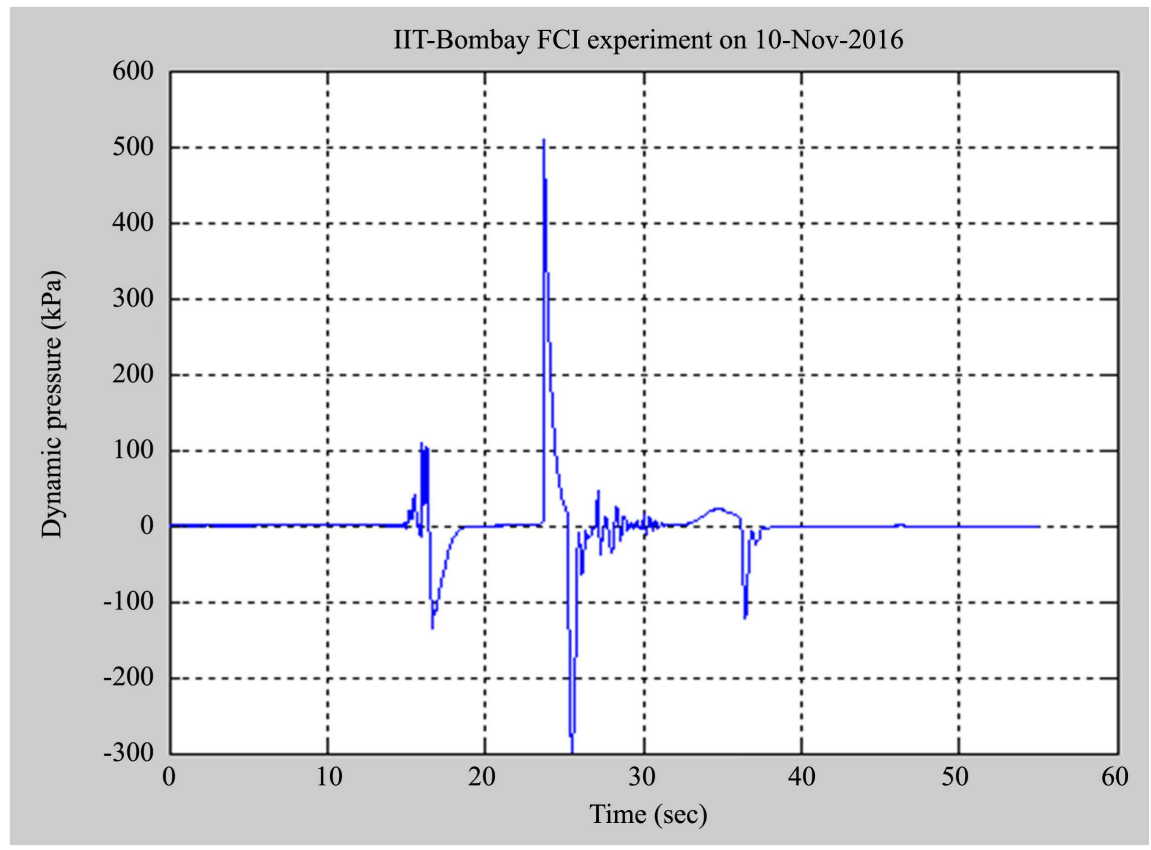

Figure 20. Dynamic pressure peak versus time curve for $\mathrm{M} / \mathrm{W}$ ratio $=0.51$.

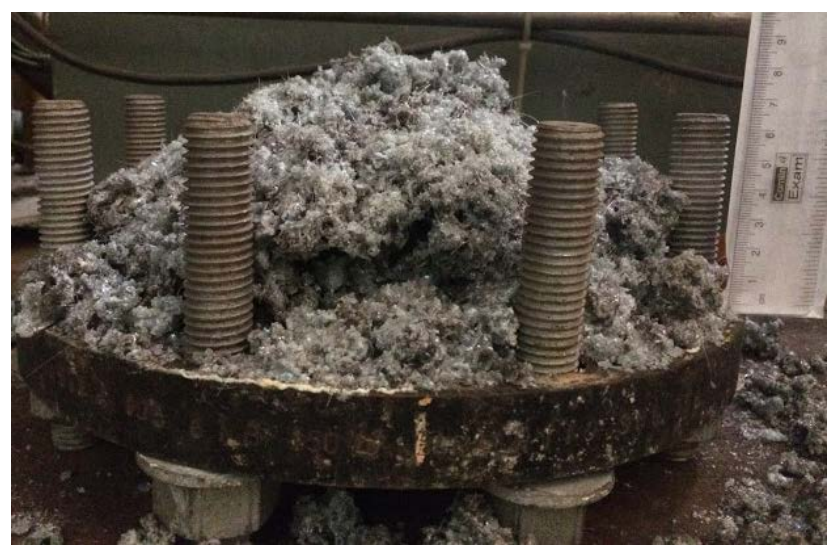

Figure 21. Debris obtained from experiment with $\mathrm{M} / \mathrm{W}=0.51$.

The results obtained from the presented study show the following:

- Sudden pressure spike was observed for the melt-to-water ratio greater than 0.21 .

- Larger melt-to-water ratio leads to the increase in number of agglomerated debris.

\section{Discussions}

If we consider the conclusions from the Moriyama's fine fragmentation theory saying that fine fragments present during FCI leads to steam explosion; the pressure spikes observed in the present study are found to be unexplainable as fine fragments were not present in this case. When the results were plotted on the Moriyama's curve, it is found that the results of the present study are lying in the no explosion zone as shown in Figure 22. Since the fragmentation theory could 


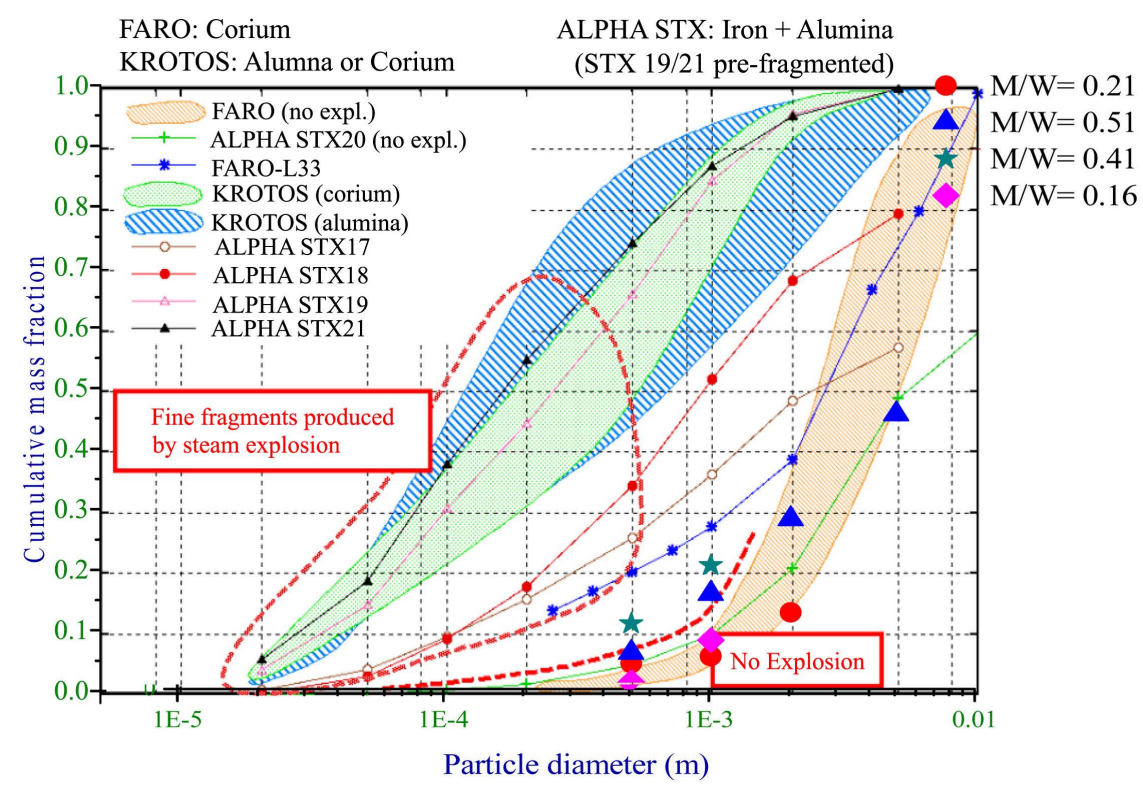

Figure 22. Analysis of present experiments using Moriyama's theory.

not explain the pressure spike observed during the FCI, we have attempted to explain the physics using the concept of conversion efficiency.

Sehgal [1] have explained the conversion efficiency as "the ratio of the mechanical energy output to the total thermal energy content of the corium mixed with water at the time the explosion occurs. 'Efficiency' is the conversion ratio expressed as a percentage of the melt thermal energy."

To evaluate the mechanical energy imparted by the dynamic pressure wave, the wave power was evaluated. In a medium, the wave power is given by Landau and Lifshitz [23] as

$$
P=\frac{A p^{2}}{\rho c} \cos \theta
$$

where,

$A$ is the area of the surface;

$\rho$ is the mass density of medium;

$c$ is the sound velocity in the medium;

$\theta$ is the angle between the direction of propagation of the wave and the normal to the surface (it is $0^{\circ}$ here).

This power was then converted into the total mechanical energy output using the duration of the peak. Evaluation of the ratio of mechanical energy over total thermal energy gives the conversion efficiency.

The conversion efficiencies for all the prior experiments were calculated from the literature and were found lying in the range of $0.3 \%-12.7 \%$ (Table 2 and Table 3), and most of them were close to $0.8 \%$. The duration of their peaks were lying in the range of 2 - 200 milliseconds. The conversion efficiencies for our tests were also found to be in the range of $0.3 \%$ to $0.70 \%$, which is of similar order (Table 4). 
Table 2. Conversion efficiencies for Alumina melt as given in the literature.

\begin{tabular}{|c|c|c|c|c|c|c|}
\hline $\begin{array}{l}\text { Melt mass } \\
\quad(\mathrm{Kg})\end{array}$ & $\begin{array}{c}\text { Melt Temperature } \\
(\mathrm{K})\end{array}$ & $\begin{array}{c}\text { Thermal energy } \\
\text { Ethermal }_{(\mathrm{kJ})}\end{array}$ & $\begin{array}{l}\text { Water } \\
\text { volume } \\
\text { (1) }\end{array}$ & $\begin{array}{c}\text { Mechanical Energy } \\
\text { E }_{\text {pressure }} \\
(\mathrm{kJ})\end{array}$ & $\begin{array}{c}\text { Conversion efficiency } \\
\eta \\
(\%)\end{array}$ & Explosion \\
\hline 1.522 & 2665 & 5040.0 & 34 & 95.3 & 1.52 & \multirow{6}{*}{ Yes } \\
\hline 1.47 & 3073 & 5707.4 & 34.6 & 60.1 & 0.87 & \\
\hline 1.539 & 2465 & 4665.3 & 34.6 & 109.1 & 2.13 & \\
\hline 1.5 & 2625 & 4883.1 & 34.6 & 76.8 & 12.7 & \\
\hline 1.5 & 2673 & 4983.9 & 33.2 & 153.2 & 2.48 & \\
\hline 1.47 & 2688 & 4915.1 & 34 & 46.1 & 2.41 & \\
\hline
\end{tabular}

Table 3. Conversion efficiencies of $\mathrm{ZrO}_{2}$ and corium melts.

\begin{tabular}{cccccccc}
\hline $\begin{array}{c}\text { Melt } \\
\text { mass } \\
(\mathrm{Kg})\end{array}$ & $\begin{array}{c}\text { Melt } \\
\text { Temperature } \\
(\mathrm{K})\end{array}$ & $\begin{array}{c}\text { Thermal } \\
\text { energy } \\
\mathrm{E}_{\text {thermal }} \\
(\mathrm{kJ})\end{array}$ & $\begin{array}{c}\text { Water } \\
\text { volume } \\
(\mathrm{l})\end{array}$ & $\begin{array}{c}\text { Pressure } \\
\text { peak } \\
(\mathrm{kPa})\end{array}$ & $\begin{array}{c}\text { Peak } \\
\text { duration } \\
(\mathbf{s})\end{array}$ & $\begin{array}{c}\text { Mechanical } \\
\text { Energy } \\
\mathrm{E}_{\text {pressure }} \\
(\mathrm{kJ})\end{array}$ & $\begin{array}{c}\text { Conversion efficiency } \\
\eta \\
(\%)\end{array}$ \\
\hline 5 & $>3373$ & $12,524.5$ & $\sim 280$ & 1000 & 0.02 & $11,084.2$ & 0.885 \\
4.2 & $>3373$ & $10,520.6$ & $\sim 280$ & 2100 & 0.0025 & 8942.5 & 0.85 \\
2.9 & 3373 & 7264.2 & $\sim 280$ & 900 & 0.008 & 3588.5 & 0.494 \\
8.4 & 3800 & $16,614.0$ & $\sim 280$ & 1000 & 0.02 & $11,081.5$ & 0.667 \\
7.7 & 2600 & $10,008.9$ & $\sim 280$ & 7000 & 0.02 & $90,470.7$ & $9.039^{*}$ \\
6.5 & 3000 & 9918.1 & $\sim 280$ & 800 & 0.02 & 7418.7 & (this was a triggered explosion) \\
\end{tabular}

Table 4. Conversion efficiencies for the present tests.

\begin{tabular}{ccccccccc}
\hline $\begin{array}{c}\text { Melt } \\
\text { mass } \\
(\mathrm{kg})\end{array}$ & $\begin{array}{c}\text { Melt } \\
\text { Temperature } \\
(\mathrm{K})\end{array}$ & $\begin{array}{c}\text { Thermal } \\
\text { Energy } \\
\mathrm{E}_{\text {thermal }}\end{array}$ & $\begin{array}{c}\text { Water } \\
\text { volume } \\
(\mathrm{kJ})\end{array}$ & $\begin{array}{c}\text { Water } \\
\text { height } \\
(\mathrm{m})\end{array}$ & $\begin{array}{c}\text { Pressure } \\
\text { peak } \\
(\mathrm{kPa})\end{array}$ & $\begin{array}{c}\text { Mechanical } \\
\text { Energy } \\
\mathrm{E}_{\text {pressure }} \\
(\mathrm{kJ})\end{array}$ & $\begin{array}{c}\text { Conversion } \\
\text { efficiency } \\
\eta\end{array}$ & $\begin{array}{c}\eta \\
(\%)\end{array}$ \\
\hline 0.925 & 1409 & 1982.2 & 4.5 & 0.27 & 506 & 13.1 & 0.7 & \\
1.846 & 1407 & 3955.9 & 4.5 & 0.27 & 467 & 13.1 & 0.33 & 0.3 \\
\hline
\end{tabular}

So, using $0.8 \%$ as the conversion efficiency and respective peak durations, the mechanical energy imparted in the form of dynamic pressure peak was estimated for all previous experiments as presented in Table 5. It was observed that the estimated peak value is close to that of measured peak value. This explains that the amount of thermal energy converting into mechanical energy, in terms of energy, is more important deciding factor for steam explosion to occur compared to the presence of fine fragments. 
Table 5. Analysis of various experimental studies performed so far using conversion efficiency theory.

\begin{tabular}{|c|c|c|c|c|c|c|c|c|c|c|c|c|c|c|}
\hline \multicolumn{15}{|c|}{ Obtaining Pressure Peak From Conversion Ratio } \\
\hline & Expt & Melt & $\begin{array}{l}\text { Melt } \\
\text { mass } \\
(\mathrm{kg})\end{array}$ & $\begin{array}{c}\text { Melt } \\
\text { Temperature } \\
\text { (K) }\end{array}$ & $\begin{array}{l}\text { Energy } \\
\text { IN } \\
\mathrm{E}_{\text {thermal }} \\
(\mathrm{kJ})\end{array}$ & $\begin{array}{l}\text { Water } \\
\text { volume } \\
\text { (l) }\end{array}$ & $\begin{array}{l}\text { Water } \\
\text { height } \\
(\mathrm{m})\end{array}$ & $\begin{array}{c}\text { Test } \\
\text { section } \\
\text { Diameter } \\
\text { (m) }\end{array}$ & $\begin{array}{l}\text { Area } \\
\left(\mathrm{m}^{2}\right)\end{array}$ & $\begin{array}{c}\text { Conversion } \\
\text { efficiency } \\
\eta \\
(\%)\end{array}$ & $\begin{array}{l}\text { Mech } \\
\text { Energy } \\
\text { E }_{\text {pressure }} \\
(\mathrm{kJ})\end{array}$ & $\begin{array}{c}\text { Estimated } \\
\text { Pressure } \\
\text { peak } \\
(\mathrm{kPa})\end{array}$ & Explosion & $\begin{array}{c}\text { Measured } \\
\text { Pressure } \\
\text { peak } \\
(\mathrm{kPa})\end{array}$ \\
\hline \multirow{5}{*}{ 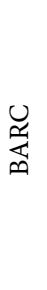 } & 5 & & 0.925 & 1409 & 1982.3 & 4.5 & 0.27 & 0.13 & 0.11 & 0.8 & 1585.8 & 462 & \multirow{5}{*}{$\begin{array}{l}\text { Pressure } \\
\text { Spike }\end{array}$} & 506 \\
\hline & 7 & $\mathrm{CaO}-\mathrm{B}_{2} \mathrm{O}_{3}$ & 1.846 & 1407 & 3956.0 & 4.5 & 0.27 & 0.13 & 0.11 & 0.8 & 3164.8 & 413 & & 467 \\
\hline & 8 & & 2.285 & 1399 & 4896.8 & 4.5 & 0.27 & 0.13 & 0.11 & 0.8 & 3917.4 & 459 & & 510 \\
\hline & & Sodium & & & & & & & & & & & & \\
\hline & 9 & $\begin{array}{c}\text { Borosilicate } \\
\text { Glass }\end{array}$ & 1.885 & 1406 & 1856.7 & 4.5 & 0.27 & 0.13 & 0.11 & 0.8 & 1485.4 & 447 & & 510 \\
\hline \multirow{6}{*}{\begin{tabular}{l}
$n$ \\
0 \\
$\qquad$ \\
0 \\
\multirow{2}{*}{}
\end{tabular}} & 38 & & 1.522 & 2665 & 5040.0 & 34 & 1.1 & 0.2 & 0.691 & 0.8 & 4032.0 & 930 & \multirow{2}{*}{ Yes } & 1000 \\
\hline & 40 & & 1.47 & 3073 & 5707.4 & 34.6 & 1.1 & 0.2 & 0.691 & 0.8 & 4565.9 & 990 & & 1000 \\
\hline & 42 & & 1.539 & 2465 & 4665.3 & 34.6 & 1.1 & 0.2 & 0.691 & 0.8 & 3732.3 & 895 & \multirow{4}{*}{ Yes } & 1000 \\
\hline & 43 & 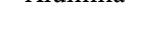 & 1.5 & 2625 & 4883.1 & 34.6 & 1.1 & 0.2 & 0.691 & 0.8 & 3906.5 & 916 & & 1000 \\
\hline & 44 & & 1.5 & 2673 & 4983.9 & 33.2 & 1.1 & 0.2 & 0.691 & 0.8 & 3987.1 & 925 & & 1000 \\
\hline & 49 & & 1.47 & 2688 & 4915.1 & 34 & 1.1 & 0.2 & 0.691 & 0.8 & 3932.1 & 919 & & 1000 \\
\hline \multirow{6}{*}{ 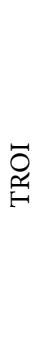 } & 1 & & 5 & $>3373$ & $12,524.6$ & & 0.67 & 0.65 & 1.37 & 0.8 & $10,019.7$ & 737 & \multirow{6}{*}{ Yes } & 1000 \\
\hline & 4 & $\mathrm{ZrO}_{2}$ & 4.2 & $>3373$ & $10,520.7$ & & 0.67 & 0.65 & 1.37 & 0.8 & 8416.5 & 1911 & & 2100 \\
\hline & 5 & & 2.9 & 3373 & 7264.3 & & 0.67 & 0.65 & 1.37 & 0.8 & 5811.4 & 888 & & 900 \\
\hline & 12 & & 8.4 & 3800 & $16,614.0$ & & 0.67 & 0.65 & 1.37 & 0.8 & $13,291.2$ & 849 & & 1000 \\
\hline & 13 & Corium & 7.7 & 2600 & $10,008.9$ & & 0.67 & 0.65 & 1.37 & 0.8 & 8007.2 & $659^{*}$ & & $7000^{\star}$ \\
\hline & 14 & & 6.5 & 3000 & 9918.1 & & 0.67 & 0.65 & 1.37 & 0.8 & 7934.5 & 656 & & 800 \\
\hline
\end{tabular}

*Triggered explosion.

\section{Further Discussions}

As discussed above, during the fuel coolant interaction, the thermal energy of the melt gets dissipated locally into the water pool, which forms a large bubble locally. This leads to thermal cavitation [24]. At the interaction surface between steam and water, the steam get trapped (may be due to pressure exerted by the water or due to localized condensation at this interface). Thus, the bubble formed here is not a perfectly vacuum but a region with relatively low steam pressure. This kind of low pressure bubble in a liquid begins to collapse due to the higher pressure of the surrounding water. As this bubble collapses, the vapour pressure increases within it. The bubble eventually collapses to a minute fraction of its original size, at which point the steam within dissipates energy into the surrounding liquid via a rather violent mechanism which releases a significant amount of energy in the form of an acoustic shock wave. This phenomenon occurs within the fraction of a second.

The shock wave or dynamic pressure peak obtained due to bubble collapse has a typical nature and contains two parts, positive and negative [24]. Once bubble 
collapses, it gives rise to the positive part of the peak representing the shock to walls of the vessel (bubble compresses until the pressure inside it is higher than outside of its boundary and then explodes leading to compression of the surrounding water). After the collapse, the surrounding water re-settles (rarefaction of the surrounding water) to occupy the volume held by the bubble, which contributes to the negative part of the peak. Peak of similar kinds were also obtained in the present experiments. Thus, steam explosion is caused by the formation and collapse of vapour bubble formed due to local deposition of thermal energy by the melt into the water. The conversion efficiency plays a key role in deciding the size of the bubble formed and hence the occurrence of steam explosion.

This phenomenology also explains the case that presence of metals in the melt increases the probability of steam explosion compared to that of oxidic melts. Metals have higher thermal conductivity compared to oxidic materials. Due to this, metallic melts transfer their thermal energies nearly instantaneously to the water and thus forming the bubble quickly. Oxidic melts take longer time to transfer their thermal energies due to low conductivity. In case, the density of the material is very high (like corium), then it will reach to the bottom of the vessel before conducting its thermal energy completely to the water and thus doesn't undergo explosive interaction with water.

It may also be noted that the studies conducted so far are lacking to capture (photographically) the formation and collapse of this bubble, formed due to thermal cavitation, may be due to lower temporal resolution in voided environment.

\section{Conclusions}

The phenomenology of steam explosion has been studied to investigate the cause and the condition for its occurrence. Several experiments have been performed and analysed to find out the root cause of the steam explosion. Following are the key findings of the present study:

- Keeping the water volume constant and varying melt amount i.e. with increase in melt-to-water ratio, after a threshold, steam explosion occurred.

- In all the experiments, the debris found were globular and larger in sizes (ranged between a few $\mathrm{mm}$ to $42 \mathrm{~mm}$ agglomerations) which could not be explained by the fact that fine fragments are needed for steam explosion to occur.

- Conversion efficiency analysis has shown that steam explosion could occur even in the absence of fine fragments. This is so because of the significant transfer of thermal energy which helps in formation of bubble.

- Conversion efficiency plays the key role in deciding the pressure spike occurred during FCI.

- Thermal cavitation gives us much clear picture of steam explosion phenomenology and it could also explain various associated phenomena.

It can thus be concluded that fine fragmentation is not the root cause for the steam explosion. It is necessary to investigate further in the direction of thermal 
cavitation phenomenology to understand steam explosion at fundamental state. Role of conversion efficiency is profound in deciding the pressure spike observed during steam explosion and this phenomenology can be used to estimate the safety margins for the systems involving possible melt-water interactions.

\section{Conflicts of Interest}

The authors declare no conflicts of interest regarding the publication of this paper.

\section{References}

[1] Sehgal, B.R. (2012) Nuclear Safety in Light Water Reactors. Elsevier Inc., Amsterdam.

[2] Board, S.J., Hall, R.W. and Hall, R.S. (1975) Detonation of a Fuel Coolant Explosion. Nature, 254, 319-321. https://doi.org/10.1038/254319a0

[3] Fletcher, D.F. and Theofanous, T.G. (1997) Heat Transfer and Fluid Dynamics Aspects of Explosive Melt-Water Interactions. Advances in Heat Transfer, 29, 129-133. https://doi.org/10.1016/S0065-2717(08)70185-0

[4] Berthoud, G. (2000) Vapor Explosions. Annual Review of Fluid Mechanics, 32, 573 611. https://doi.org/10.1146/annurev.fluid.32.1.573

[5] OECD/NEA Reports (2007 and 2015) Steam Explosions.

[6] Magallon, D., Huhtiniemi, I. and Hohmann, H. (1999) Lessons Learnt from FARO/ TERMOS Corium Melt Quenching Experiments. Nuclear Engineering and Design, 189, 223-238. https://doi.org/10.1016/S0029-5493(98)00274-X

[7] Magallon, D. and Huhtiniemi, I. (2001) Corium Melt Quenching Tests at Low Pressure and Subcooled Water in FARO. Nuclear Engineering and Design, 204, 369-376. https://doi.org/10.1016/S0029-5493(00)00318-6

[8] Magallon, D. (2006) Characteristics of Corium Debris Beds Generated in LargeScale Fuel-Coolant Interaction Experiments. Nuclear Engineering and Design, 236, 1998-2009. https://doi.org/10.1016/j.nucengdes.2006.03.038

[9] Kaiser, A., Huber, F. and Wilhelm, D. (1998) Experiments on the Behaviour of a Hot Melt Injected into Sodium. Experimental Thermal and Fluid Science, 18, 48-69. https://doi.org/10.1016/S0894-1777(98)10008-0

[10] Moriyama, K., Maruyama, Y. and Nakamura, H. (2002) A Simple Evaluation Method of the Molten Fuel Amount in a Premixing Region of Fuel-Coolant Interactions. Journal of Nuclear Science and Technology, 39, 53-58.

https://doi.org/10.1080/18811248.2002.9715156

[11] Corradini, M.L., Kim, B.J. and Oh, M.D. (1988) Vapor Explosions in Light Water-Reactors-A Review of Theory and Modeling. Progress in Nuclear Energy, 22, 1-117. https://doi.org/10.1016/0149-1970(88)90004-2

[12] Corradini, M.L. (1991) Vapor Explosions: A Review of Experiments for Accident Analysis. Nuclear Safety, 32, 337-362.

[13] Cho, D.H., Armstrong, D.R. and Anderson, R.P. (1995) Combined Vapor and Chemical Explosions of Metals and Water. Nuclear Engineering and Design, 155, 405-412. https://doi.org/10.1016/0029-5493(94)00885-3

[14] Mitchell, D.E., Corradini, M.L. and Tarbell, W.W. (1981) Intermediate Scale Steam Explosion Phenomena: Experiments and Analysis. NUREG/CR-2145, SAND81-0124. 
[15] Yamano, N., Maruyama, Y., Kudo, T., Hidaka, A. and Sugimoto, J. (1995) Phenomenological Studies on Melt-Coolant Interactions in the ALPHA Program. Nuclear Engineering and Design, 155, 369-389. https://doi.org/10.1016/0029-5493(94)00883-Z

[16] Hohmann, H., Magallon, D., Schins, H. and Yerkess, A. (1995) FCI Experiments in the Aluminium Oxide-Water System. Nuclear Engineering and Design, 155, 391-403. https://doi.org/10.1016/0029-5493(94)00884-2

[17] Kudinov, P., Karbojian, A., Ma, W. and Dinh, T.N. (2010) The DEFOR-S Experimental Study of Debris Formation with Corium Simulant Materials. Nuclear Technology, 170, 219-230. https://doi.org/10.13182/NT10-A9460

[18] Kudinov, P., Davydov, M., Pohlner, G., Bürger, M., Buck, M. and Meignen, R. (2012) Validation of the FCI Codes against DEFOR-A Data on the Mass Fraction of Agglomerated Debris. The European Review Meeting on Severe Accident Research, ERMSAR 2012, Cologne, 21-23 March 2012, Validation of the FCI Codes against DEFOR-A Data on the Mass Fraction of Agglomerated Debris Session 2.

[19] Kudinov, P., Karbojian, A., Tran, C.T. and Villanueva, W. (2013) Agglomeration and Size Distribution of Debris in DEFOR-A Experiments with $\mathrm{Bi}_{2} \mathrm{O}_{3}-\mathrm{WO}_{3} \mathrm{Co}$ rium Simulant Melt. Nuclear Engineering and Design, 263, 284-295. https://doi.org/10.1016/j.nucengdes.2013.06.011

[20] Kudinov, P. and Davydov, M. (2013) Development and Validation of Conservative-Mechanistic and Best Estimate Approaches to Quantifying Mass Fractions of Agglomerated Debris. Nuclear Engineering and Design, 262, 452-461. https://doi.org/10.1016/j.nucengdes.2013.05.020

[21] Moriyama, K. and Park, H.S. (2014) Challenges in Thermohydraulic Analysis of LWR Severe Accidents: Steam Explosion. IW-NRTHS 2014: International Workshop on New Horizons in Nuclear Reactor Thermal Hydraulics and Safety, Vol. I, 91.

[22] Paladino, D., Theerthan, S.A. and Sehgal, B.R. (2002) DECOBI: Investigation of Melt Cool Ability with Bottom Coolant Injection. Progress in Nuclear Energy, 40, 161-206. https://doi.org/10.1016/S0149-1970(01)00022-1

[23] Landau, L.D. and Lifshitz, E.M. (1987) Fluid Mechanics: Landau and Lifshitz: Course of Theoretical Physics. Vol. 6, Pergamon Press, Oxford. https://doi.org/10.1016/B978-0-08-033933-7.50009-X

[24] Brennen, C.E. and Christopher, E. (1995) Cavitation and Bubble Dynamics. Annual Review of Fluid Mechanics, 9, 145-185. 